\title{
A Novel Method for Modeling Lowest-Level Vertical Motion
}

\author{
ThOMAs E. RobINSON ${ }^{\mathrm{a}, \mathrm{b}}$ AND STEVEN BUSINGER \\ University of Hawai'i at Mānoa, Honolulu, Hawaii
}

(Manuscript received 20 April 2018, in final form 15 May 2019)

\begin{abstract}
A new method for modeling the lowest model level vertical motion is described and validated. Instead of smoothing terrain heights, the new method calculates the terrain gradient on a high-resolution grid and averages the gradient values around a gridpoint location. In essence, the method provides a way to achieve some of the impact of very steep terrain on the flow without the computational overhead associated with the very high grid resolution needed to fully resolve complex terrain. The more accurate depiction of the terrain gradient leads to an increase in orographic vertical motion and causes rainfall to occur more often over the windward-facing mountain slopes, consistent with observations. Model results are compared with rain gauge data during the month of January 2016 as well as radar data from a case study on 9 March 2012. When implemented in the Weather Research and Forecasting (WRF) Model over the island of Oahu and compared with the current WRF method, the model precipitation forecast skill is improved. The new method produces more precipitation over the island during January 2016, which is closer to the observed value. On 9 March 2012, the new method clearly focuses the precipitation over the Ko'olau Mountains, reducing the number of false alarm forecasts by nearly one-half. Although the changes to model precipitation skill were small, they were generally positive.
\end{abstract}

\section{Introduction}

Because orography plays an important role in the distribution of precipitation over land, accurately modeling the influence of mountains on the atmosphere is imperative to providing reliable forecasts and model output for climatological applications. Mountains are stationary on the time scale of weather, which means they cannot actively cause precipitation. Instead they serve as a location of reorganization of storm systems that already exist (Houze 2012). Although Houze (2012) mentions that trade wind precipitation in Hawaii can be considered an exception, in that there are still many instances where incoming clouds and precipitation systems are enhanced by the orography of the Hawaiian Islands.

Lin et al. (2001) provide a mathematical connection between orography and precipitation. They begin with a precipitation equation:

\footnotetext{
a ORCID: 0000-0001-5553-0226.

${ }^{\mathrm{b}}$ Current affiliation: Geophysical Fluid Dynamics Laboratory, Princeton, New Jersey.
}

Corresponding author: Thomas E. Robinson, ter@hawaii.edu

$$
P=E(w q) \frac{L_{s}}{C_{s}},
$$

where $P$ is the total precipitation $(\mathrm{m}), E$ is the precipitation efficiency (ratio of rain rate to condensation and deposition), $w$ is the vertical motion: change of height with time $\left(\mathrm{m} \mathrm{s}^{-1}\right), q$ is the moisture $\left(\mathrm{g} \mathrm{g}^{-1}\right), L_{s}$ is the horizontal storm scale $(\mathrm{m})$, and $c_{s}$ is the storm speed $\left(\mathrm{m} \mathrm{s}^{-1}\right)$. They then split $w$ into two parts:

$$
w=w_{\text {oro }}+w_{\text {env }},
$$

where $w$ is the vertical motion, $w_{\text {oro }}$ is the orographically enhanced vertical motion, and $w_{\text {env }}$ is the vertical motion of the environment. Because $w_{\text {oro }}$ is a function of mountain height $h(x, y)$, the orographic vertical motion can be represented by

$$
w_{\text {oro }}=\frac{D h(x, y)}{D t} \mathbf{v} \cdot \nabla h
$$

where $t$ is time and $\mathbf{v}$ is the horizontal wind vector. Lin et al. (2001) then continue to expand the gradient of mountain height $\nabla h$ into horizontal components so that the full equation for $w_{\text {oro }}$ is 


$$
w_{\text {oro }}=u \frac{\partial h}{\partial x}+v \frac{\partial h}{\partial y}
$$

with $u$ and $v$ representing the zonal and meridional wind components, respectively. Assuming that there is enough moisture for precipitation, increasing the horizontal wind or the gradient of the mountains will result in an increase in precipitation when (4) is substituted back into (1). There are six additional factors that contribute to orographic precipitation based on these equations: high precipitation efficiency of the upstream air; concave mountain cirques relative to the incoming flow; strong synoptic vertical motion; high amounts of water vapor present in the incoming air; the presence of a large synoptic system; and a slow-moving system (Lin et al. 2001). Additionally, a conditionally unstable or unstable atmospheric profile can lead to an increase in orographic precipitation (Doswell et al. 1996).

Mountain shape is an important influence on precipitation location and amount. Using an idealized Weather Research and Forecasting (WRF) Model simulation, Watson and Lane (2012) found that concave mountains produce more confluence and precipitation enhancement. They also found that small adjustments to wind direction influence the amount and location of orographic precipitation. When the wind blows directly into a concave feature's vertex, the precipitation along the mountain is higher than if the wind is rotated $5^{\circ}$. An accurate depiction of mountain shape is necessary to model orographic precipitation.

For this modeling study, the Hawaiian Island of Oahu was selected because of its strong terrain gradients (Fig. 1). Over Windward Oahu, rainfall distribution patterns often follow the shape of the Ko'olau Mountains, signaling a strong connection between orography and rainfall (Schroeder 1977). The concave shape of the mountains on the island plays an important role in influencing the location of precipitation (Murphy and Businger 2011).

The precipitation over the mountains on the Hawaiian Islands can be orders of magnitude higher than over the surrounding ocean (Kodama and Businger 1998). The most rainfall over the islands occurs above $500 \mathrm{~m}$ and along the slopes facing the prevailing wind. Precipitation tends to fall over an extended period of time and not just a single convective event. The absence of a trade wind inversion combined with the aforementioned factors provides the most likely scenario and location for heavy precipitation events (Kodama and Barnes 1997). Moist southeasterly winds and synoptic disturbances are often involved in flooding and enhanced by orographic effects (Murphy and Businger 2011, Kodama and Barnes 1997, Lyman et al. 2005). Rainfall events that do

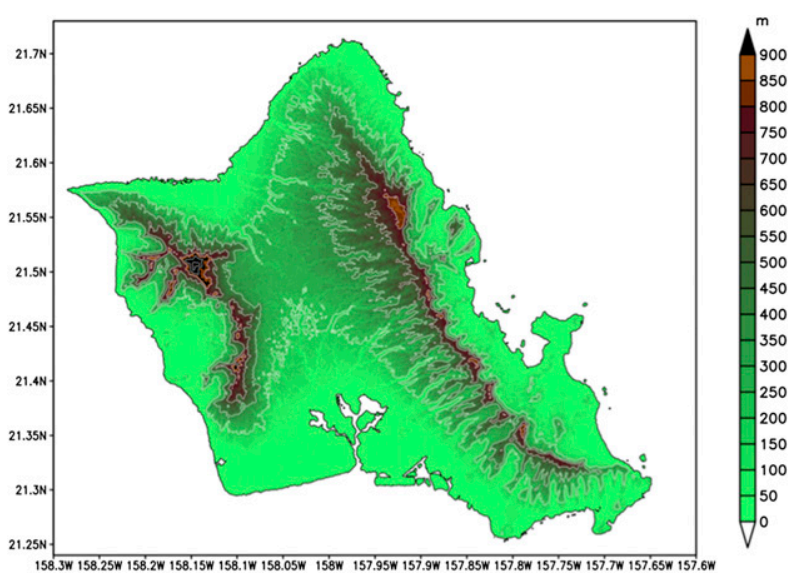

FIG. 1. Topographic map of Oahu. White contours are every $250 \mathrm{~m}$. Color shading changes every $50 \mathrm{~m}$ up to $900 \mathrm{~m}$. Heights above $900 \mathrm{~m}$ are black. The Ko'olau Mountains are the range on the east side of Oahu, and the Waianae Mountains are to the west.

not produce flooding occur within the trade wind flow and are typically called trade showers (Van Nguyen et al. 2010, Chen and Nash 1994, Chen and Feng 1995).

The WRF Model has been used in previous precipitation studies over the Island of Oahu (Van Nguyen et al. 2010, Hartley and Chen 2010). Terrain data with resolution of $0.0005^{\circ}(\sim 50 \mathrm{~m})$ is available, but most weather models, such as the WRF Model, use a much lower resolution grid. This allows the WRF Model to complete calculations of the computationally expensive processes of the atmosphere in a reasonable time frame.

Under resolving the terrain gradient can lead to an underestimation of precipitation (Lyman et al. 2005). Many studies that simulate orographic precipitation utilize simple models that have higher resolution than would be available with a full physics model. Schär and Smith (1993) used a shallow-water model to simulate the blocking effects of mountains on the flow. An upslope linear model with simple microphysics (Smith 2003, Smith and Barstad 2004) has also been used, and further extended to include vertical layers (Barstad and Schüller 2011).

In the normal preprocessing stage of a WRF run, highresolution terrain is smoothed to fit the WRF Model grid spacing. When the model calculates vertical motion, the detail of the terrain gradient is lost because of the smoothing of the terrain. To recapture some of the lost terrain detail, a new method of calculating the vertical motion in the lowest level of the WRF Model has been developed using the terrain gradient equation (4). This new method provides the WRF Model with a better representation of the vertical motion at the lowest level of the model, which leads to an improvement in the skill of precipitation prediction associated with orographic 
impacts. This method is similar to what WRF Model already does with a small difference: it calculates the terrain gradient on the high-resolution terrain data, and then smooths the gradient to calculate the vertical motion. The WRF Model smooths the high-resolution terrain data, and then calculates the terrain gradient from the smoothed data. The new method switches the order that the smoothing is done, which keeps some of the gradient information that may be lost when smoothing the heights.

\section{Data and methods}

\section{a. WRF Model setup}

For this set of experiments, the WRF Model is run on a $220 \times 170$ single domain with 3000 -m grid spacing encompassing the main Hawaiian Islands. There are 40 vertical levels spaced on the order of tens of meters for the levels nearest the ground, with first model level at $\sim 17 \mathrm{~m}$ above the surface, and gradually increasing in distance between levels with height. Input data for the WRF Model are the $1^{\circ}$ National Centers for Environmental Prediction (NCEP) FNL Operational Model Global Tropospheric Analyses datasets. The increase in terrain resolution to the 3000-m WRF domain should be acceptable because the study is looking at isolated islands in the Pacific Ocean.
The WRF physics package used includes WRF single-moment 6-class scheme, which resolves ice, snow, and graupel processes suitable for high-resolution simulations (Hong and Lim, 2006); the Mellor-YamadaJanjić (MYJ) planetary boundary layer scheme (Janjić 2002), which solves the prognostic equation for the TKE; the RRTM longwave-shortwave radiation scheme (Mlawer et al. 1997); and a simple downward integration that efficiently allows efficiently for clouds and clear-sky absorption and scattering (Dudhia 1989). The physics setup is the same as the setup for the Mauna Kea Weather Center operational WRF Model runs (https:// tinyurl.com/ybq2p7pb).

\section{b. WRF modification}

During each time step of a typical WRF Model run, the lowest-level vertical motion is calculated by taking the difference between the terrain height at the point of interest $h(i, j)$, and the height at the next point in the meridional $[h(i, j+1)]$ or zonal direction $[h(i+1, j)]$, then multiplying the difference by the meridional or zonal wind ( $v$ and $u$ ), respectively. Those quantities are added together in the given direction, divided by double the grid spacing $(0.5 d x$ or $0.5 d y)$. The zonal and meridional components are then added together. The equation is

$$
\begin{aligned}
w(i, j)= & 0.5 d y\{v(i, j+1)[h(i, j+1)-h(i, j)]+v(i, j)[h(i, j)-h(i, j-1)]\} \\
& +0.5 d x\{u(i+1, j)[h(i+1, j)-h(i, j)]+u(i, j)[h(i, j)-h(i-1, j)]\},
\end{aligned}
$$

where $w$ is the vertical motion calculated by WRF in the lowest sigma level; $i$ and $j$ are the points in the zonal and meridional direction; $d x$ and $d y$ are the WRF grid spacing in the zonal and meridional direction, respectively; $u$ and $v$ are the horizontal winds on the Arakawa$\mathrm{C}$ staggered grid in the zonal and meridional direction, respectively; and $h$ is the terrain height.

High-resolution terrain data $\left(0.0005^{\circ}\right)$ from the U.S. Geological Survey are used to calculate the highresolution terrain gradient over Oahu. First, the distance between each point is calculated and found to be $51.7 \mathrm{~m}$ in the zonal direction and $55.6 \mathrm{~m}$ in the meridional direction assuming a constant distance between points in the $1^{\circ} \times 1^{\circ}$ box that the data are obtained from. Next, the gradient of the terrain is found for all of the points over the Island of Oahu using finite center differencing. Then a latitude and longitude square is formed around each point in the WRF Model, and the values of the high-resolution terrain gradients in the zonal and meridional direction are averaged within each box. This causes a smoothing of the gradient in the area surrounding a grid point instead of smoothing the terrain heights by taking the value at the grid point.

Using (4), the finite-difference approximation vertical motion equation is

$$
w(i, j)=v(i, j) \frac{d h}{d y}(i, j)+u(i, j) \frac{d h}{d x}(i, j),
$$

where $d h / d x$ and $d h / d y$ are the averaged gradient of the terrain in the zonal and meridional direction, respectively. By using this method, other portions of the model where the terrain would be used are unaffected, but the vertical motion calculation is more representative of the interaction between the surface wind and the slope of orography (discussed in section 3a). The subroutine is called for every time step of the WRF run.

\section{c. Model runs}

The original (CTRL) and modified (EXP) WRF Models were run daily producing 30 -h forecasts starting 


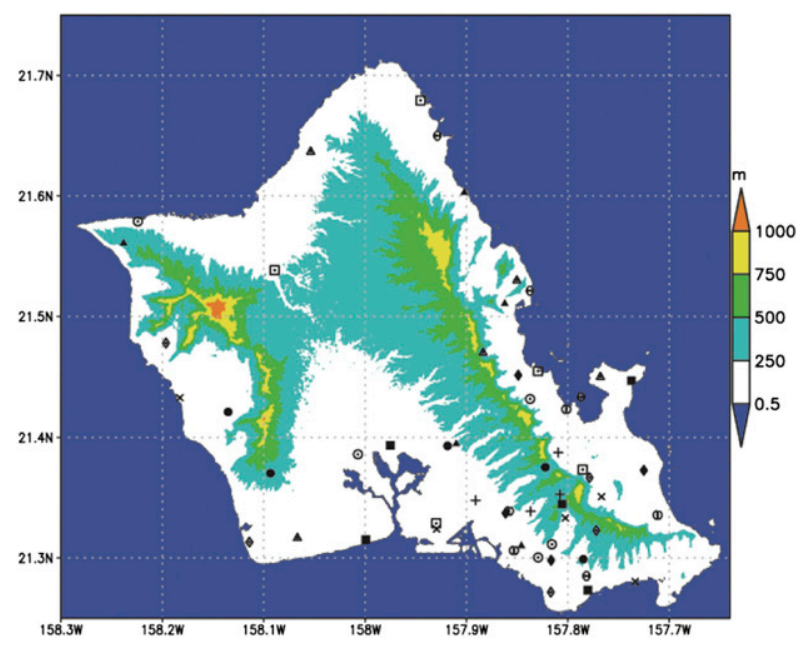

FIG. 2. Map of rain gauge locations around the island of Oahu. Each gauge is marked with a dot, square, diamond, or triangle. High-resolution terrain heights are plotted every $250 \mathrm{~m}$.

at 1800 UTC for the month of January 2016. This month long study is done to compare the long-term predictive skill of the old and new methods. The first $6 \mathrm{~h}$ of the forecast are ignored to allow for spinup because the initial vertical motion is calculated using the original method in both models. This allows both models to spin up from the same initial conditions, with the change in terrain calculation occurring at the first time step in the EXP runs. After ignoring the first 6 forecast hours for spinup, the output data from each model run are a $24-\mathrm{h}$ time series starting at 0000 UTC. The setup is designed to simulate generating daily operational precipitation forecasts accumulated over $24 \mathrm{~h}$ using the WRF Model.
Model verification of precipitation is done using daily rain gauge data from the National Centers for Environmental Information daily summaries dataset. There are 56 rain gauges that reported rainfall data across the island. The locations of the gauges (Fig. 2) are spread out across the island of Oahu, but the majority are on the eastern windward part of the island to the east of $158^{\circ} \mathrm{W}$. The data run from 3 to 30 January, and the reports are in millimeters of rain per 24-h period starting at 0800 Hawaiian standard time (HST) the previous day. The minimum observable amount is $0.3 \mathrm{~mm}$. If a station was missing data, then the time period of missing data was skipped for that station. This month-long study compares the long-term predictive skill of the old and new methods.

Using the WRF forecast, a case study was run for $24 \mathrm{~h}$ starting at 0000 UTC 9 March 2012 to show comparisons of the models during a single high-impact orographic rainfall event. During this time, a synoptic-scale upperlevel low pressure system was over the area causing widespread precipitation over several of the Hawaiian Islands including Oahu. First, a WRF Model control run is performed. Next, the EXP model is run and the CTRL and EXP forecasts are qualitatively compared. The CTRL and EXP models are then compared with the Weather Surveillance Radar-1988 Doppler (WSR-88D) located on the island of Moloka' $i$ at $21.132^{\circ} \mathrm{N}, 157.179^{\circ} \mathrm{W}$ (PHMO). The S-band (10.0-cm wavelength) radar has a nominal peak output of $750 \mathrm{~kW}$, pulse width of $1.57 \mu \mathrm{s}$, and pulse repetition frequency between 318 and $1304 \mathrm{~s}^{-1}$ (Crum and Alberty 1993). For the rainfall analysis, a 30-min average of the $0.5^{\circ}$ reflectivities is taken every $15 \mathrm{~min}$ starting from 0000 to 1730 UTC 9 March 2012. For example, the
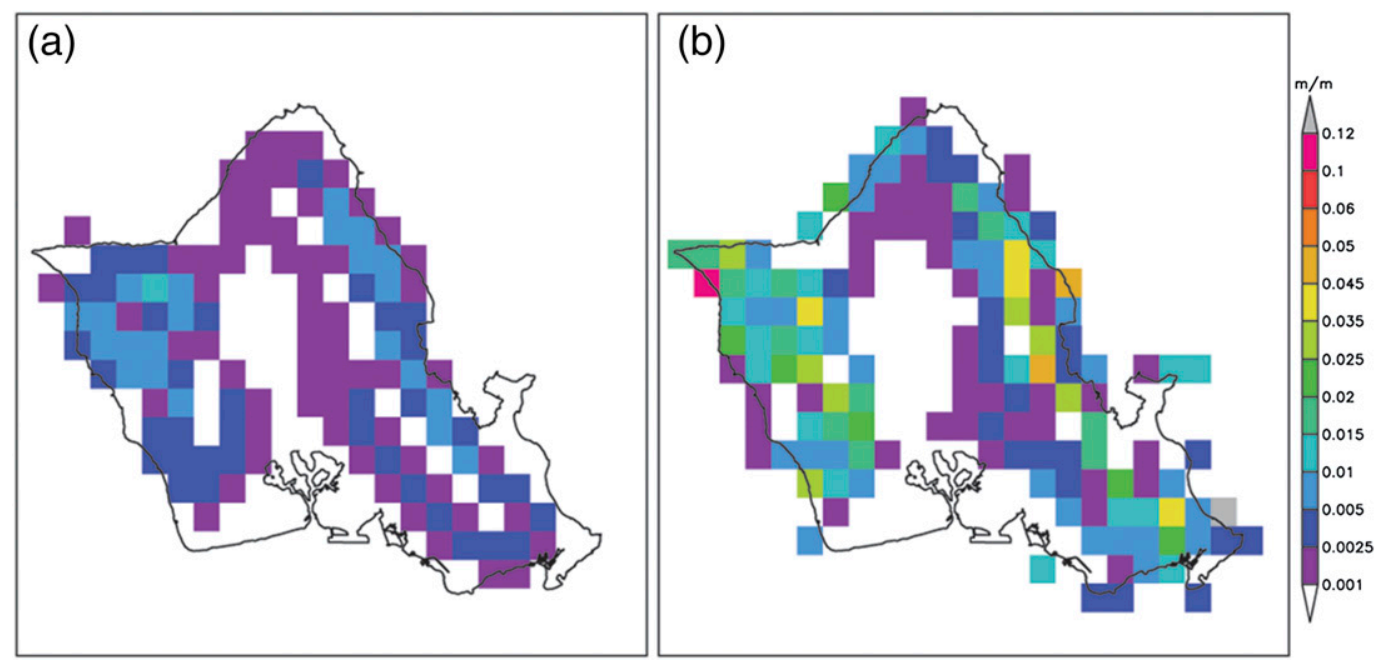

FIG. 3. Terrain gradient used at each grid point in WRF over Oahu for (a) CTRL and (b) EXP. 
TABLE 1. Summary of January 2016 rainfall observations, modeled rainfall, and errors in the model.

\begin{tabular}{lc}
\hline \hline No. of rain gauge stations & 56 \\
Rain gauge rainfall total (mm) & 1219.4 \\
CTRL rainfall total (mm) & 668 \\
EXP rainfall total (mm) & 709.4 \\
Percent error CTRL & $45.2 \%$ \\
Percent error EXP & $41.8 \%$ \\
Total count of observed rain & 306 \\
Total count of no observed rain & 998 \\
Total count of observations & 1304 \\
Percent error CTRL during rain & $23.2 \%$ \\
Percent error EXP during rain & $22.8 \%$ \\
\hline
\end{tabular}

average reflectivity at a given point at 0300 UTC would be the average of radar reflectivity from 0245 to 0315 UTC.

The 15-min WRF Model precipitation output is compared to the radar reflectivity in order to examine how well the model performs using the $2 \times 2$ contingency table method from Wilks (2011, chapter 7). The nonprobabalistic discrete variable measured is the occurrence of rainfall at a given location. In order for the model forecast to be considered a hit, a radar reflectivity of at least $15 \mathrm{~dB} Z$ must occur in a model grid box that precipitation is forecast to fall, or an adjacent grid box to the predicted precipitation point in any horizontal direction. Using two of the $Z-R$ relationships employed by the National Weather Service (NWS), a radar reflectivity of $15 \mathrm{dBZ}$ corresponds to a rainfall rate of $0.245 \mathrm{~mm} \mathrm{~h}^{-1}$ $\left(0.01 \mathrm{in} . \mathrm{h}^{-1}\right)$ according to the summertime deep convection $Z-R$ relationship (Birchard 1999) and $0.200 \mathrm{~mm} \mathrm{~h}^{-1}$ using the Marshall-Palmer $Z-R$ relationship (Marshall and Palmer 1948). By using this definition of a hit along with the 30-min reflectivity average, some spatial and temporal leeway is given to the model. False alarms occur when the model predicts precipitation, but the radar reflectivities in the predicted grid box and adjacent points are all less than $15 \mathrm{dBZ}$. Misses occur when there is precipitation in a grid box, but the model forecasts none. Correct rejections happen when the model correctly predicts no precipitation in a grid box.

A similar $2 \times 2$ contingency table was produced for the January 2016 daily rainfall. If at least $0.3 \mathrm{~mm}$ of rain (the minimum detectable by the gauge) was observed and modeled at the same location, then the forecast is considered a hit. If the model forecast at least $0.3 \mathrm{~mm}$ of rain but none was observed, then the forecast is a false alarm. If at least $0.3 \mathrm{~mm}$ of rain was observed but less than $0.3 \mathrm{~mm}$ was forecast it is considered a miss and if no precipitation was observed and less than $0.3 \mathrm{~mm}$ was forecast, it is considered a correct rejection. For the purpose of the contingency table, the amount of precipitation is not considered.

\section{Results \\ a. Gradient differences}

The terrain gradient for the old method (Fig. 3a) is several times smaller than the gradient produced by the new EXP WRF (Fig. 3b). To the west of the Kaneohe Peninsula, both models have a local maximum, but the gradient is about 0.045 in EXP and 0.007 in CTRL. In this case, the two models agree on the location of the strongest terrain incline, but the magnitude of the gradient of the EXP model is approximately 6.5 times higher than the CTRL. To the north and slightly west, the values are about 3.5 times different in the same location.

There are several sections where the EXP model produced a different terrain shape as well. Over the

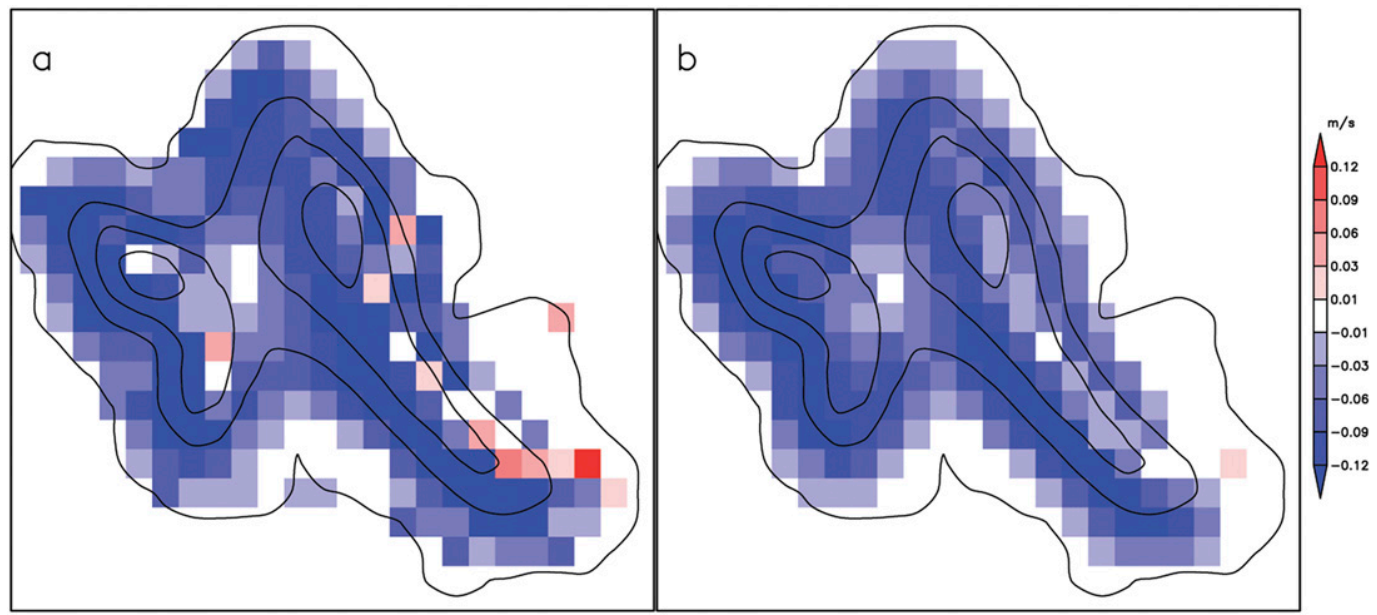

FIG. 4. Average vertical motion during the month of January 2016 over the Island of Oahu for the lowest WRF Model sigma level for (a) EXP and (b) CTRL. Black contours are drawn for terrain heights every $150 \mathrm{~m}$. 


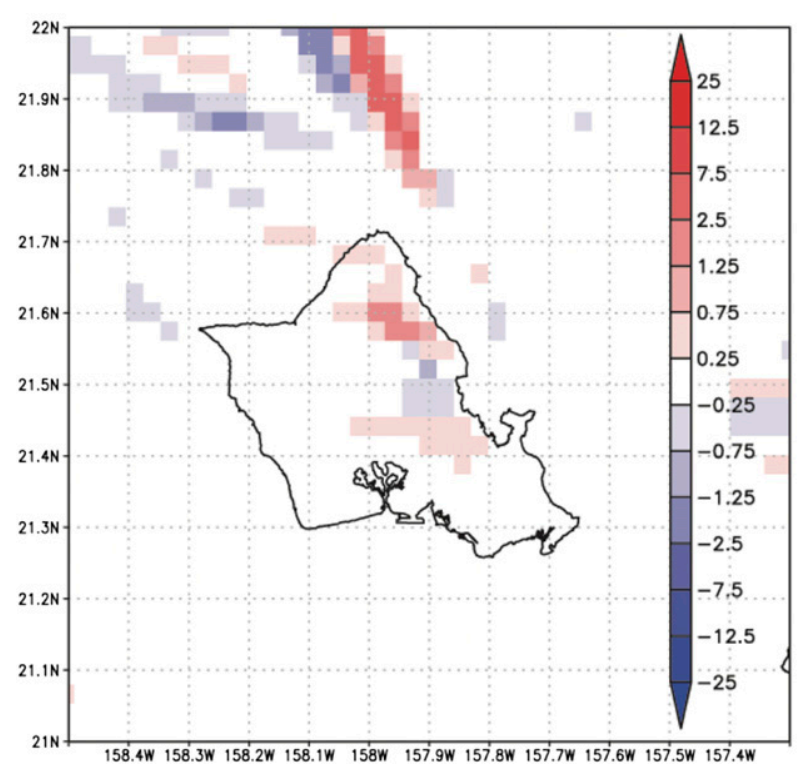

FIG. 5. Total precipitation difference $(\mathrm{mm})$ in $24 \mathrm{~h}$ between EXP and CTRL model runs over and around the Island of Oahu on $6 \mathrm{Jan}$ 2016. Positive values indicate where the EXP model produced more precipitation than CTRL.

Kaneohe Peninsula on the eastern part of the island, the EXP terrain includes variations in slope associated with small hills, whereas the CTRL model sees this region as flat. On the southeast corner of the island, the EXP model shows strongest variation in terrain, over $0.12 \mathrm{~m} \mathrm{~m}^{-1}$, but the CTRL model sees this region as flat. The cliffs along the ocean on the eastern side of Oahu are very steep (Fig. 1) so the EXP model clearly shows an improvement over the CTRL model.

The terrain gradient over the western side of the island also shows a more realistic gradient in the EXP model. The northwest section of Oahu is mostly flat along the coast with high mountains just inland. This is well represented in the EXP model along the northern and western sections of the coast going out to Kaena Point (the northwest corner of Oahu). In the CTRL model, these mountain gradients are more scattered and not nearly as strong.

\section{b. January 2016 comparisons}

To show long-term results, rain gauge data are compared to model data during the month of January 2016 (Table 1). Section $3 \mathrm{c}$ is a single case study to show specific results during an individual event. Throughout the entire month, the rain gauges recorded $1219.4 \mathrm{~mm}$ of rain. The EXP model produced more overall precipitation at the rain gauge locations $(709.4 \mathrm{~mm})$ compared to the CTRL model runs $(668 \mathrm{~mm})$. Although this is only a $6 \%$ increase, it turns out to be about $1.4 \mathrm{~mm} \mathrm{day}^{-1}$

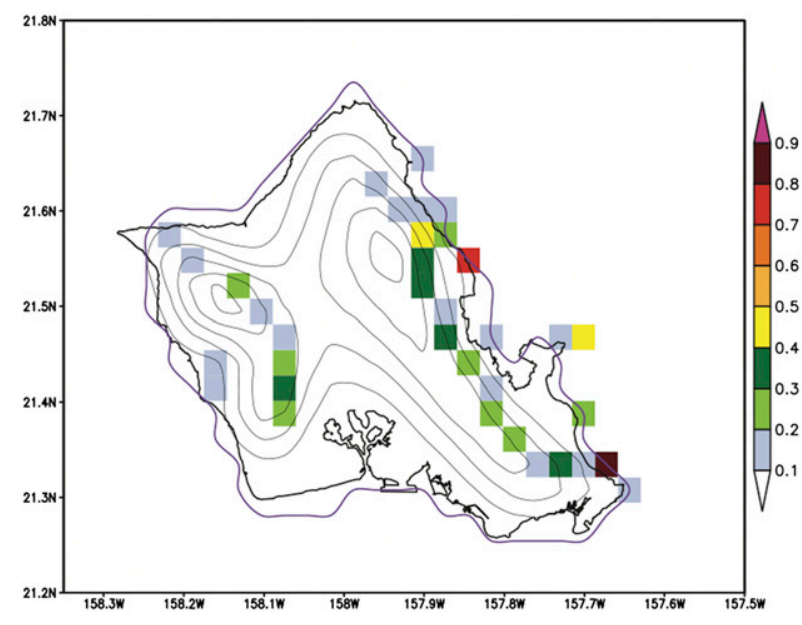

FIG. 6. Difference between the 24-h average vertical motion $\left(\mathrm{m} \mathrm{s}^{-1}\right)$ from EXP minus CTRL for the lowest WRF Model sigma level, showing positive values only over the Island of Oahu. The thick black line shows the high-resolution coastline of the island, and black elevation contours occur every $100 \mathrm{~m}$. The purple line represents the WRF Model land mask.

$\left(0.05\right.$ in. day $\left.{ }^{-1}\right)$. The percent error in comparing EXP and CTRL to the observations is $41.8 \%$ and $45.2 \%$, respectively. The EXP model produces more precipitation and is closer to the observations than the CTRL model during the month of January.

The upward motion is stronger in the EXP model compared to the CTRL model over the month, especially on the windward side of the island. There are a few points on the windward side of the Ko'olau Mountains to the east where the average vertical motion is positive (Fig. 4a) in the EXP model. The CTRL model is almost entirely downward motion except for a single grid point southeast of the island (Fig. 4b). The same grid point on the EXP model has a vertical motion value that is much higher.

The EXP model does a slightly better job than CTRL during the month of January when precipitation actually occurs. In considering only when rainfall was observed, the EXP model's percent error is $22.8 \%$, but the CTRL model is $23.2 \%$. This small improvement is due to the EXP model usually producing more precipitation because of the increase in lowest-level vertical motion.

A box that contains the rain gauges with the bounds being between $21.325^{\circ}-21.400^{\circ} \mathrm{N}$ and $157.75^{\circ}-157.85^{\circ} \mathrm{W}$ was analyzed to consider rainfall only in the region of the Ko'olau Mountain slope. There was $434 \mathrm{~mm}$ of rain observed at these stations during the month of January. The CTRL model produced $202 \mathrm{~mm}$ of precipitation, whereas the EXP model predicted $191 \mathrm{~mm}$. There were many times when precipitation was predicted but did not occur. Considering only when precipitation occurred, 


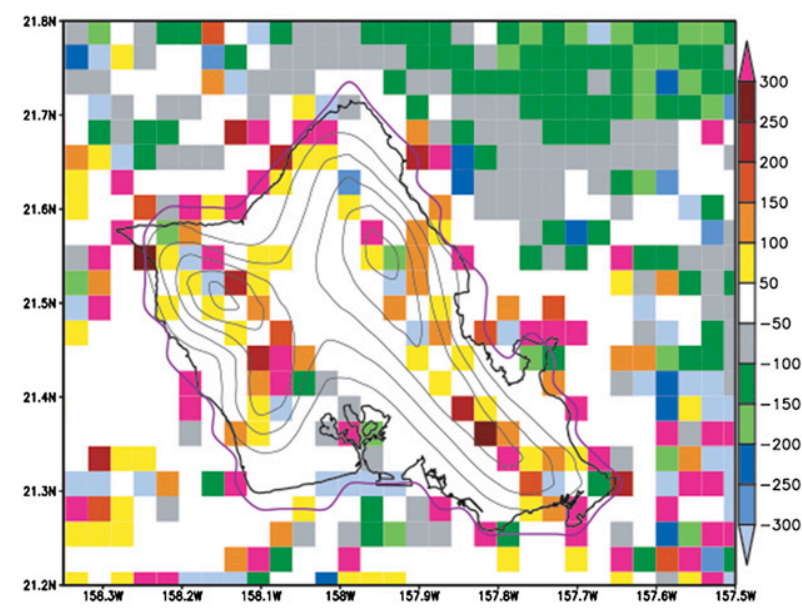

FIG. 7. Percent difference between the 24-h average vertical motions $\left(\mathrm{m} \mathrm{s}^{-1}\right)$ on the WRF lowest model sigma level from EXP minus CTRL runs over Oahu. Terrain contours are as in Fig. 6.

the CTRL and EXP models both over predicted the amount of precipitation. The CTRL model had an average of $311 \%$ error for rainfall predicted during an observed rainfall event. The EXP model did better with an average of $279 \%$ error for the same period.

During orographic rain events, the EXP model clearly shows more precipitation, especially in the area of the Ko'olau Mountains (Fig. 5). When precipitation occurs over the Ko'olau Mountains on 6 January 2016, the EXP model produces higher precipitation in that area. The increased terrain gradient causes an increase in the lowest-level vertical motion, which leads to an increase in the enhancement of orographic precipitation in the WRF Model. The location of offshore precipitation to the north of the island also changes. Both model runs forecast that precipitation, but differ slightly on the location. It is speculated that the small changes in the model caused by the different low-level vertical motion calculation causes feedback that leads to slight changes in the other fields of the model.

\section{c. Case study of 9 March 2012}

On 9 March 2012, strong wind shear and very large buoyancy associated with a vigorous shortwave trough aloft contributed to the development of severe thunderstorms over Oahu. In the early hours of the morning, heavy precipitation occurred along the Ko'olau Mountains, and a supercell formed along the windward side ( $\sim 1500$ UTC) that produced large hail in Kaneohe and a tornado in Lanikai. A 10-cm hailstone was observed near Kaneohe and verified by the NWS, breaking the all-time record for the state of Hawaii. This storm was chosen for a case study because the Ko'olau Mountains significantly influenced the heavy precipitation.

The EXP and CTRL model runs produced different vertical motion patterns on the lowest model sigma level. The upward motion is stronger along most of the Ko'olau Mountains' windward side in the EXP run (Fig. 6). This is a result of the increased gradient along the slope of the mountain. On the northern part of the island, a difference of $\sim 0.7 \mathrm{~m} \mathrm{~s}^{-1}$ occurs in one of the grid boxes (yellow square in Fig. 6). In reality, there is a small mountain in that area over $500 \mathrm{~m}$ high (Fig. 1), but that feature is absent in the 3-km terrain of the CTRL model. Along the southeast coast, there is a difference of $0.8 \mathrm{~m} \mathrm{~s}^{-1}$ associated with a small cliff right near the coast that is also absent in the low-resolution WRF terrain. Each point

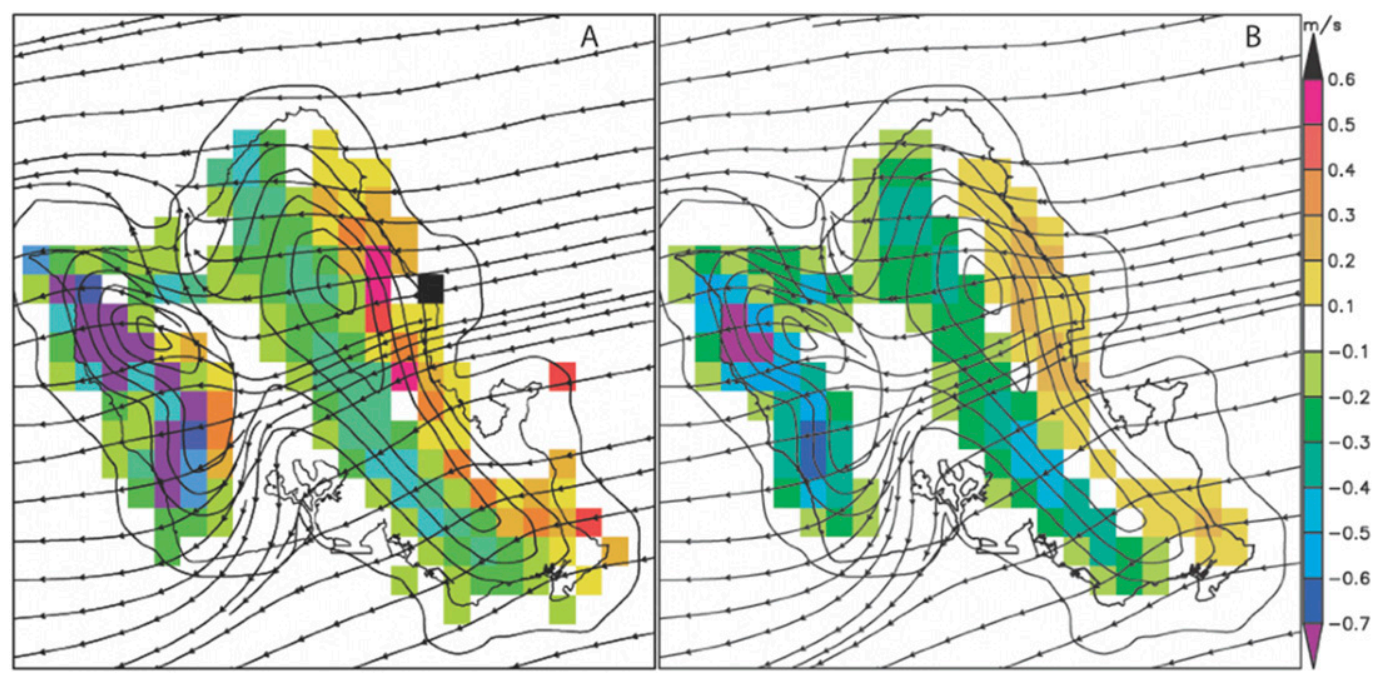

FIG. 8. Lowest sigma level WRF vertical motion (color) and horizontal wind direction (streamlines) overlaid on terrain heights every $100 \mathrm{~m}$ at 1500 UTC 9 Mar 2012. (a) EXP run and (b) CTRL run. 


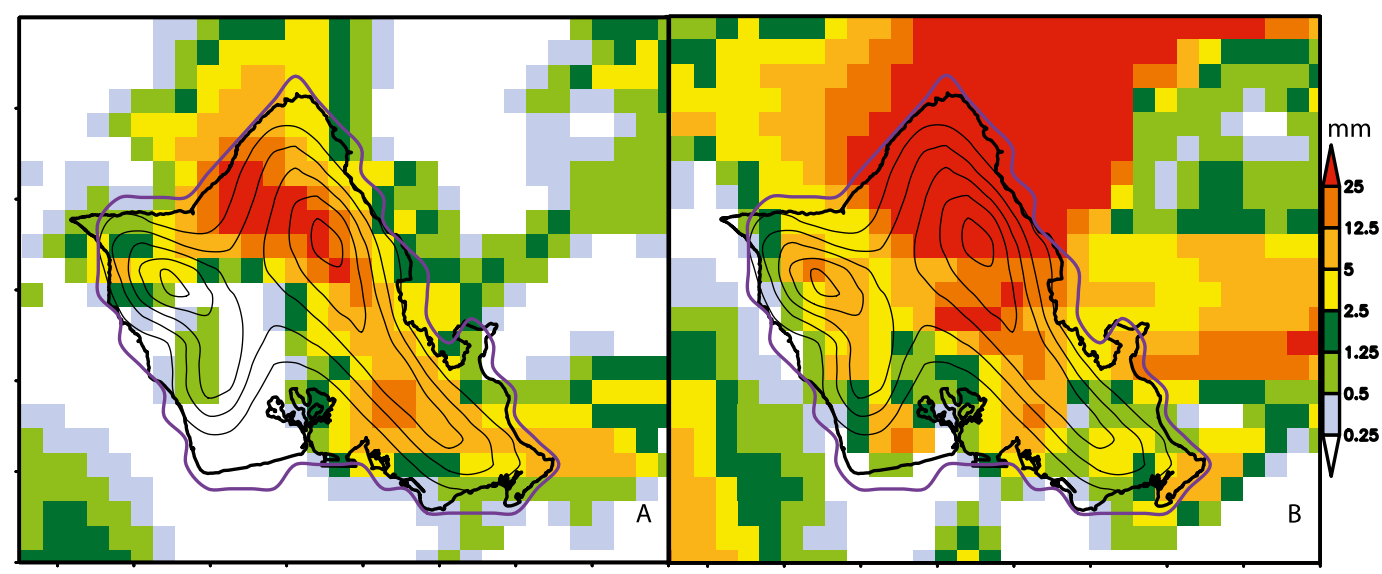

FIG. 9. Total precipitation (mm) from 0000 to 1800 UTC 9 Mar 2012 from the WRF Model for the (a) EXP run and (b) CTRL run over the Island of Oahu. The terrain contours are the same as in Fig. 6.

along the mountain slope where the vertical motion is larger in the EXP run (Fig. 6) is associated with either a small concave cirque or a very sharp terrain gradient in the high-resolution terrain (Figs. 1 and 3).

The vertical motion maxima are stronger in the EXP model compared to the CTRL model at any given time (Fig. 7). At 1500 UTC (Fig. 8), the maximum in vertical motion in EXP is over $0.6 \mathrm{~m} \mathrm{~s}^{-1}$, but in CTRL the maximum is between 0.2 and $0.3 \mathrm{~m} \mathrm{~s}^{-1}$.

The change in vertical motion caused changes in the modeled precipitation patterns. The EXP model run produced precipitation that was mainly focused over the Ko'olau Mountains, with a distinct northern and southern maximum (Fig. 9a). There was also some precipitation right off the southeast coast. The middle of the island stays mostly dry, likely because of the downward motion on the lee side of the mountains and most of the moisture falling on the windward side. In the CTRL run (Fig. 9b), a large area of precipitation occurred along the northeastern part of the island that extended well off to the northeast. The modeled precipitation swath is much larger and the rainfall totals are much higher, especially over the northern part of the island and ocean. More moisture is able to advect over the mountain because the vertical motion is weaker leading to more precipitation over the middle of the island compared to the EXP run. There was some precipitation that fell over the southeastern part of the island, but the main focus of the event occurred to the north. Neither model was able to generate the supercell or the heaviest precipitating cells along the Ko'olaus to the north. This is likely due to the low resolution $(3 \mathrm{~km})$ compared to the scale of the convection and low-level initiation of those storms. The positive difference between subtracting Fig. 9a and Fig. 9b shows that the EXP model run puts more precipitation over the mountains in the southeastern part of the island as well as just to the south of the northern peak of the Ko'olaus (Fig. 10). Heavy precipitation events often occur in conjunction with terrain anchoring (Schroeder 1977), and the precipitation is more anchored to the mountains in the EXP run, because of the increase in vertical motion along the slope.

The PHMO radar made observations every $4 \mathrm{~min}$ and $40 \mathrm{~s}( \pm 1 \mathrm{~s})$ at the $0.5^{\circ}$ elevation angle. Between 0003 and 1801 UTC, there were 232 observations. During that time period, radar reflectivity returns were observed over the Ko'olau Mountains for almost the entire time period (Fig. 11), with most of the reflectivities occurring near the northern peak, to the west and southwest of Kaneohe, and within the southeastern valleys of the island. The storm is anchored to the terrain consistent

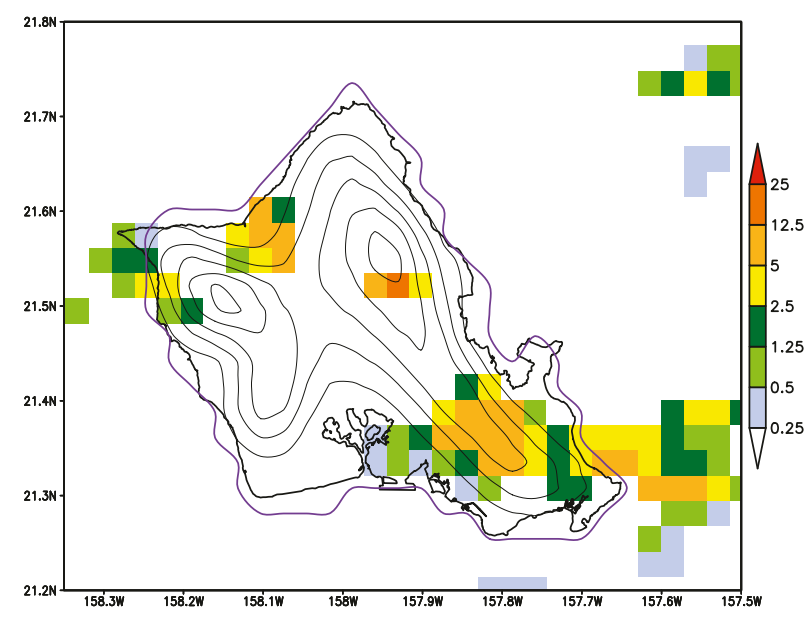

FIG. 10. The positive difference in total rainfall between EXP and CTRL from 0000 to 1800 UTC 9 Mar 2012. This is essentially the positive values of Fig. 9a minus Fig. 9b. The terrain contours are the same as in Fig. 6. 


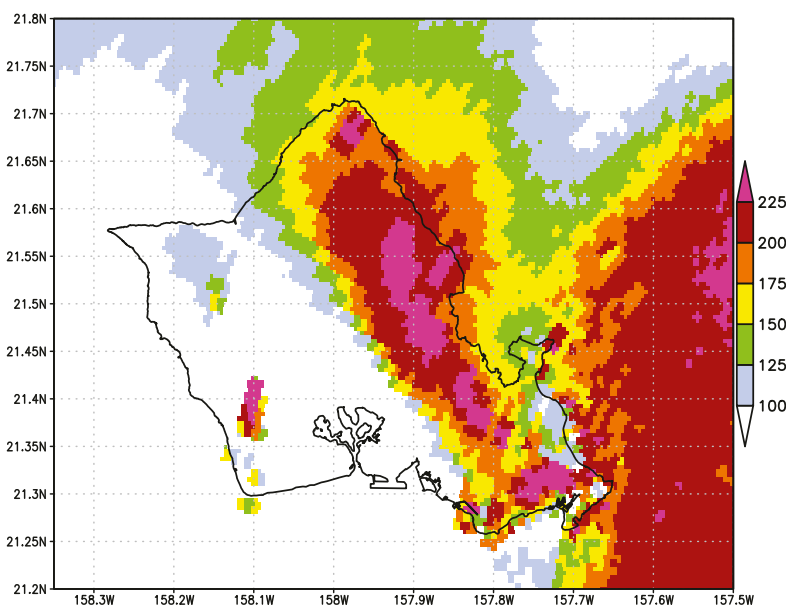

FIG. 11. Number of times a radar return of at least $0 \mathrm{dBZ}$ occurred at a given point from 0003 to 1801 UTC 9 Mar 2012 over the island of Oahu (outlined in black).

with the EXP model run. These areas of high hydrometeor concentration from the radar coincide with the areas of rainfall better forecast by the EXP model than the CTRL model (Fig. 9). The area to the west and southwest of Kaneohe shows up in both the radar high activity region (Fig. 11) and the EXP model (Fig. 9a).

The amount of precipitation forecast during the entire time period from 0000 UTC 9 March to 0000 UTC 10 March is generally improved over the Island of Oahu by the EXP model. Out of the 21 rain gauges that have data available during the event (Fig. 12), the EXP model is closer to the observed at 13 locations (Table 2). Some of the percent error is very large, but the error is large in both models. HI-11 and HI-30 both had observations of over $100 \mathrm{~mm}$ of rain, however, neither model predicted over $10 \mathrm{~mm}$. There are some good improvements with the EXP model, most notably at HI-23 where the EXP model and observations were very close and the CTRL model was very different.

One location that the CTRL model more accurately predicted more precipitation was at $\mathrm{HI}-10$ on the northeast part of the island (Fig. 12). Both the EXP (Fig. 13a) and CTRL (Fig. 13b) predicted large areas of precipitation. These large precipitation areas had strong lowlevel convergent winds associated with thunderstorm development. The CTRL model produced one of those thunderstorms close to the northeast part of the island which propagated on shore. The pattern and path of the storm produced in the CTRL is not supported by the radar reflectivity (Fig. 14), so in the case of HI-10, the quantity of precipitation improvement is right for the wrong reasons. Most of the heavy precipitation that occurred over the island, especially on the windward

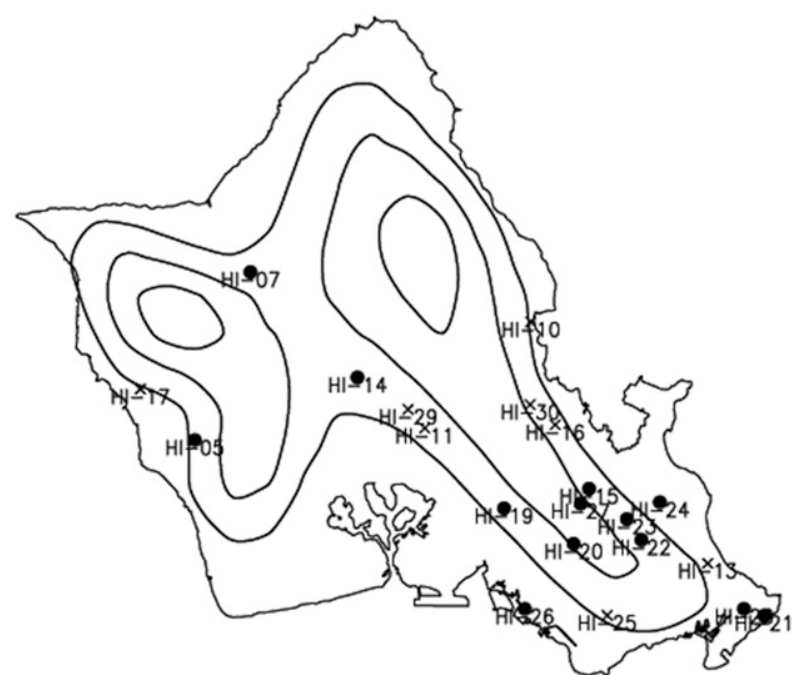

FIG. 12. Location of 21 stations from Table 2 with 200-m terrain height contours. Locations with a black dot indicate that the EXP model precipitation was closer to the observations, and gauges marked with an $\mathrm{X}$ are where the CTRL model precipitation was closer to the observed.

side, was orographic rainfall and there was no large off shore thunderstorm that propagated on shore.

The precipitation differences away from the mountains between the CTRL and EXP can be attributed to changes in the transport of mass in the model. By changing the low-level vertical motion, the horizontal wind field must be modified to maintain balance in the continuity equation. Although the changes to the horizontal winds are small (Fig. 8) they are present. These changes affect the location and magnitude of the convergence in the model, which in turn changes the precipitation. These dynamical considerations should be considered when evaluating the differences in the model output fields. A deeper dive into how the dynamics are affected by changing the low-level vertical motion is a topic for future research.

\section{d. Forecasts of rainfall}

Using the $15-\mathrm{dB} Z$ threshold described in section $2 \mathrm{c}$, the EXP model has fewer hits, more misses, fewer false alarms, and more correct rejections than the CTRL model (Table 3). The proportion of correct forecasts for the EXP model (0.94) is slightly better than for the CTRL model (0.93). Overall the CTRL model is wetter and has almost exactly double the number of false alarms as the EXP model. The false alarm ratio is 0.06 for EXP compared to 0.11 for CTRL. This means that $11 \%$ of the forecasted precipitation in the CTRL model was not observed by the PHMO radar. This false alarm rate led to an increase in threat score from 0.79 for the EXP run compared to 0.76 for the CTRL run. The number of bad 
TABLE 2. Observed and modeled rainfall $(\mathrm{mm})$ for the 21 gauges around Oahu.

\begin{tabular}{lcrr}
\hline \hline Gauge & Obs & CTRL & EXP \\
\hline HI-05 & 2.03 & 5.11 & 1.04 \\
HI-07 & 12.95 & 3.03 & 7.24 \\
HI-10 & 41.4 & 17.97 & 3.97 \\
HI-11 & 17.02 & 11.69 & 2.58 \\
HI-13 & 3.3 & 1.25 & 6.06 \\
HI-14 & 8.64 & 25.93 & 1.94 \\
HI-15 & 41.4 & 1.42 & 7.31 \\
HI-16 & 104.39 & 7.59 & 6.15 \\
HI-17 & 6.1 & 0.64 & 0.33 \\
HI-19 & 25.15 & 13.72 & 19.23 \\
HI-20 & 53.85 & 0.34 & 9.37 \\
HI-21 & 3.05 & 6.49 & 5.66 \\
HI-22 & 22.61 & 0.74 & 5.53 \\
HI-23 & 10.41 & 0.74 & 10.88 \\
HI-24 & 32 & 1.35 & 2.43 \\
HI-25 & 20.07 & 2.59 & 2.44 \\
HI-26 & 1.78 & 3.31 & 3.06 \\
HI-27 & 47.5 & 1.42 & 7.31 \\
HI-28 & 4.06 & 6.49 & 5.66 \\
HI-29 & 7.87 & 11.69 & 2.58 \\
HI-30 & 131.06 & 7.59 & 6.15 \\
\hline
\end{tabular}

forecasts (false alarms and misses) in the EXP model (3310) compared to the CTRL model (3842) leads to the probability of a correct rejection to be 0.56 and 0.54 , respectively. The CTRL model has a higher probability of a hit (0.069) compared to EXP (0.061), but the probabilities are very close to each other. The Gilbert Skill Score for EXP is higher at 0.725 and for CTRL is 0.698. The models produce statistically similar results because most of the dynamics and physics are identical, but the increase in model skill for this particular event can only be attributed to the improved methodology of calculating the lowest-level vertical motion.

The EXP and CTRL runs have similar patterns where they had the most hits (Figs. 15a and 15b), which lines up with where precipitation occurred. The increased misses that the EXP model experienced happened in the northern part of the domain over the ocean, especially to the northwest (Fig. 15c). The increase in low-level vertical motion caused more precipitation to occur over the mountains and potentially modified some of the local regional effects to prevent of some of the heavier precipitation over the ocean away from the orography, specifically to the northwest (Fig. 9). The higher vertical motion causes more anchoring to the mountains in EXP. The CTRL run had more misses off the eastern coast of Oahu (Fig. 15d), especially to the east of Kaneohe.

There is a large reduction in false alarms for EXP (Fig. 15e) compared to CTRL (Fig. 15f). The CTRL run over predicts precipitation over the ocean, especially to the northeast of the island (Fig. 9b), which is the cause of most of the false alarms. There are also more false alarms over the ocean just to the north and east of the Kaneohe Peninsula. Because the CTRL run does not focus the precipitation along the mountain as is observed, the CTRL run produces an abundance of false alarms that do not occur in the EXP run. Both model runs have a similar false alarm pattern over southern central Oahu where the terrain influence is less important because the orography is lower. The pattern for correct rejections is very similar in both models, with the EXP model (Fig. 15g) having a few more correctly forecasted dry areas on the southern part of the Ko'olau Mountains than the CTRL model (Fig. 15h). Because the precipitation is more anchored

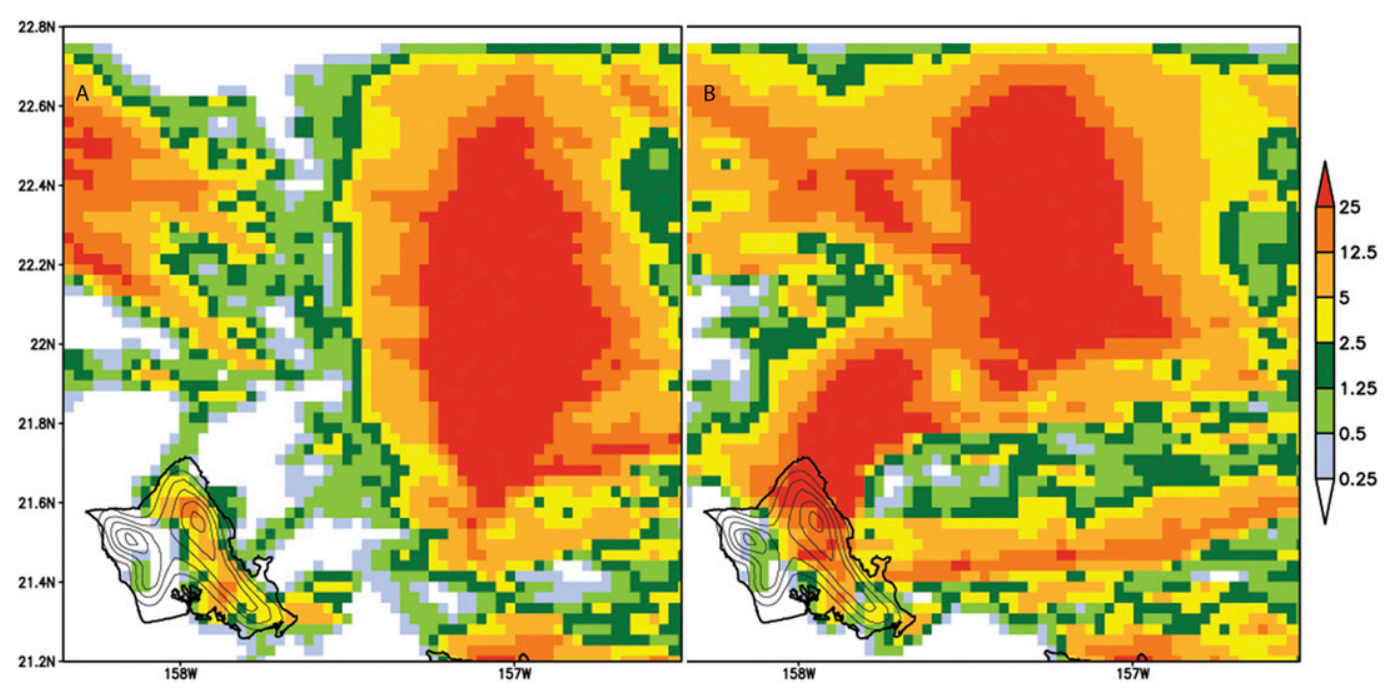

FIG. 13. As in Fig. 9, but over a wider area. 


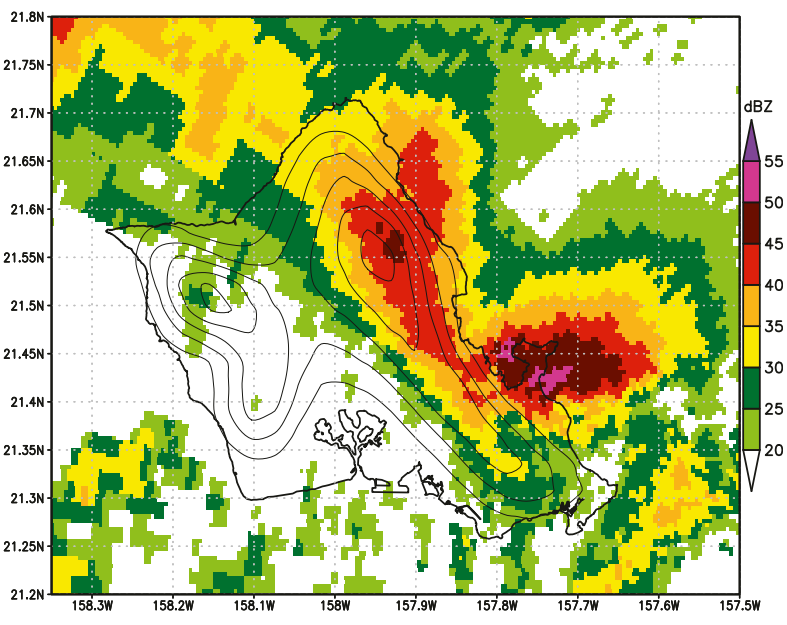

FIG. 14. Average radar reflectivity from PHMO over the Island of Oahu from 0003 to 1801 UTC 9 Mar 2012 with terrain contours as in Fig. 6.

over the mountains, the leeward side appears to be drier in the EXP model run.

The number of correct forecasts (hits and correct rejections) is higher in the EXP run (52 490) than the CTRL run (51227). The EXP model shows improvement over the ocean to the east of the state. The EXP model (Fig. 16a) and CTRL model (Fig. 16b) have large differences in accuracy counts over the ocean. The EXP model does a better job of keeping precipitation over the mountains by creating an area of strong low-level vertical motion. The orographic effects in the CTRL model are much weaker due to the reduced terrain gradient, so it incorrectly forecasts more precipitation over the ocean.

To the northeast of the domain and north and east of the Kaneohe Peninsula, the EXP model clearly outperforms the CTRL run. The CTRL run over predicts precipitation in that area (Fig. 9b). Over the Ko'olau Mountains, the two models have very similar counts of accurate forecasts, but the EXP run produces higher hit counts on the southeastern part of the island. This is where the EXP run produces more precipitation than the CTRL run (Fig. 10). The enhanced lowest-level vertical motion calculation provides for a more accurate depiction of precipitation occurrence than the normal calculation done by the WRF Model because the terrain-induced vertical motion is closer to reality in the EXP model.

The false alarms over the ocean discussed above account for most of the difference between the EXP and CTRL model runs. Most of the bad forecasts that occur in the EXP run (Fig. 16c) occur in the northwestern part of the domain and over south and central Oahu. The CTRL run's bad forecasts occur over south and central Oahu and over the ocean to the east and northeast of the island (Fig. 16d). The CTRL model shows a large increase in false alarms due to the precipitation not being focused over the mountains, which leads to the EXP run outperforming the CTRL run. The CTRL model has more widespread precipitation, but the EXP run produces a more realistic forecast because the moisture is focused over the mountains. This more accurate depiction of the Ko'olau Mountain's gradient in the EXP run provides an increase in accuracy and a decrease in the false alarm rate in the modified WRF Model run. Scaling the high-resolution terrain gradient to calculate the model's lowest-level vertical motion improves the skill and accuracy of the model as well as greatly reducing the false alarm ratio. The full effect of how changing the low-level vertical motion on the overall dynamics of the model is an area for future research.

During the month of January 2016, the $2 \times 2$ contingency table (Table 4) shows an improvement in precipitation occurrence forecasts as well. Using the daily rain gauge data, an observation or modeled precipitation is considered a "yes" if at least $0.3 \mathrm{~mm}$ of rainfall occurs

TABLE 3. At top left, the relationship between counts of radar observed precipitation and forecast precipitation occurrence on 9 March 2012 for the EXP model run. The top right is as for the top left, but for the CTRL run. At bottom left, percentages of total occurrences from the top left. The bottom right is as for the bottom left, but for the CTRL run.

\begin{tabular}{|c|c|c|c|c|c|c|c|}
\hline \multicolumn{4}{|c|}{ Counts for EXP } & \multicolumn{4}{|c|}{ Counts for CTRL } \\
\hline & & \multicolumn{2}{|c|}{ Observed } & & & \multicolumn{2}{|c|}{ Observed } \\
\hline & & Yes & No & & & Yes & No \\
\hline \multirow[t]{5}{*}{ Forecast } & Yes & 12136 & 782 & Forecast & Yes & 12731 & 1566 \\
\hline & No & 2528 & 40354 & & No & 2276 & 39227 \\
\hline & \multicolumn{3}{|c|}{ Percentage for EXP } & \multicolumn{4}{|c|}{ Percentage for CTRL } \\
\hline & & \multicolumn{2}{|c|}{ Observed } & & & \multicolumn{2}{|c|}{ Observed } \\
\hline & & Yes & No & & & Yes & No \\
\hline \multirow[t]{2}{*}{ Forecast } & Yes & 21.8 & 1.4 & Forecast & Yes & 22.8 & 2.8 \\
\hline & No & 4.5 & 72.3 & & No & 4.1 & 70.3 \\
\hline
\end{tabular}






FIG. 15. Number of forecasts on 9 Mar 2012 where (a) the EXP run correctly predicted precipitation to occur (hit). (b) As in (a), but for the CTRL run. (c) The EXP run predicted no precipitation, but precipitation did occur (miss). (d) As in (c), but for the CTRL run. (e) The EXP run predicted precipitation, but the precipitation did not occur (false alarm). (f) As in (e), but for the CTRL run. (g) The EXP run correctly predicted no precipitation to occur (correct rejection). (h) As in (g), but for the CTRL run. The color bar at the bottom applies to all panels. 


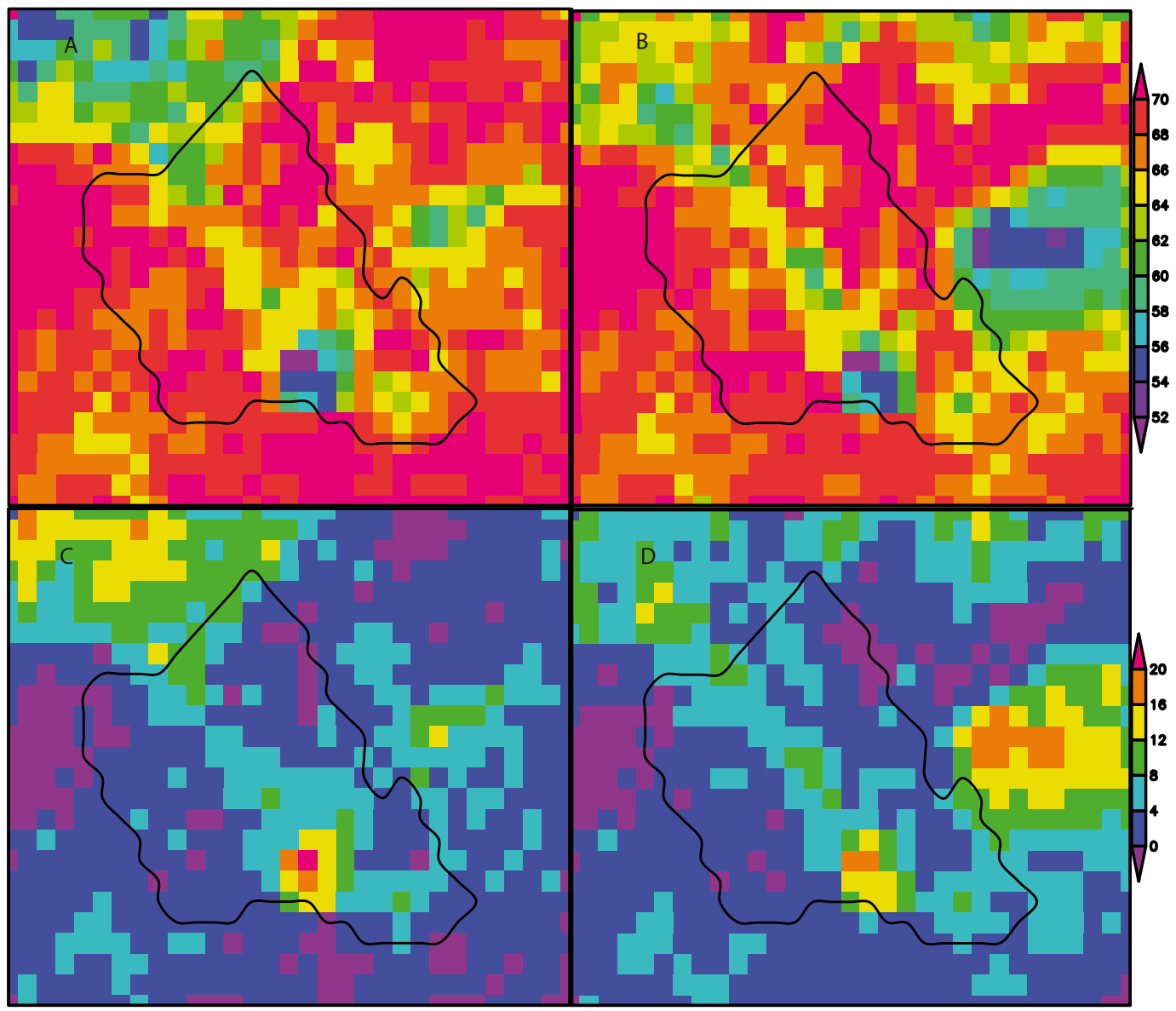

FIG. 16. (a) Total number of correct precipitation forecasts on 9 Mar 2012 from EXP run. (b) As in (a), but from the CTRL run. (c) Total number of incorrect forecasts from EXP. (d) As in (c), but from CTRL.

during the course of the day, otherwise it is considered a "no." The correct forecasts of precipitation in EXP (175) produce a 5\% change over the CTRL (167). Similarly, the number of misses in EXP (131) is 5\% better than CTRL (139). The forecasts related to precipitation not occurring are almost identical, which shows that the EXP model is more useful during precipitation events but is the same as CTRL during times when precipitation is not occurring. As the other methods of analyzing the data point out, the improvement is marginal but positive.

\section{Conclusions}

A new method to compute the lower boundary condition of the WRF Model was derived from a highresolution $(\sim 50 \mathrm{~m})$ terrain gradient. Instead of fitting the high-resolution terrain to the WRF Model domain and then calculating the gradient and multiplying it by the horizontal wind, the high-resolution terrain gradient was fit to the WRF Model and used to calculate the vertical motion at the lowest model level. By smoothing the terrain gradient instead of the terrain heights to calculate the lowest-level vertical motion, the model produces higher values of vertical motion along the windward face of the mountain (Fig. 6). In essence, the method provides a way to achieve some the impact of very steep terrain on the flow, without the computational overhead associated with the very high grid resolution needed to fully resolve complex terrain. The new method produces more rain in the area of the mountains when orographic precipitation occurs (Fig. 5). This results in a more accurate forecast in the WRF Model because of the change in the vertical motion pattern (Table 3).

The model skill increased for forecasting the occurrence of precipitation during the severe thunderstorm event on 9 March 2012, because the model depicts the terrain gradient more realistically. Neither model run was able to reproduce the supercell that moved over the Kaneohe Peninsula or heavy storm cells on the northern part of the Ko'olau Mountains. It is suggested that the WRF Model was unable to reproduce the stronger updrafts present 
TABLE 4. At top left, the relationship between daily rain gauge observed precipitation and forecast precipitation occurrence for the EXP model run. The top right is as for the top left, but for the CTRL run. At bottom left, percentages of total occurrences from the top left. The bottom right is as for the bottom left, but for the CTRL run.

\begin{tabular}{|c|c|c|c|c|c|c|c|}
\hline \multicolumn{4}{|c|}{ EXP } & \multicolumn{4}{|c|}{ CTRL } \\
\hline & & \multicolumn{2}{|c|}{ Observed } & & & \multicolumn{2}{|c|}{ Observed } \\
\hline & & Yes & No & & & Yes & No \\
\hline \multirow[t]{2}{*}{ Forecast } & Yes & 175 & 131 & Forecast & Yes & 167 & 139 \\
\hline & No & 252 & 746 & & No & 251 & 747 \\
\hline \multicolumn{4}{|c|}{ Percentage for EXP } & \multicolumn{4}{|c|}{ Percentage for CTRL } \\
\hline & & \multicolumn{2}{|c|}{ Observed } & & & \multicolumn{2}{|c|}{ Observed } \\
\hline & & Yes & $\overline{\mathrm{No}}$ & & & Yes & No \\
\hline \multirow[t]{2}{*}{ Forecast } & Yes & 13.4 & 10.1 & Forecast & Yes & 12.8 & 10.7 \\
\hline & No & 19.3 & 57.2 & & No & 19.2 & 57.3 \\
\hline
\end{tabular}

within a supercell storm, because of the relatively coarse resolution $(3 \mathrm{~km})$ of the WRF Model runs.

During an entire month of forecasts, the model error in the precipitation forecasts is slightly reduced by using the new terrain gradient method (Table 1). The precipitation occurrence forecast is only $5 \%$ more accurate (Table 4). The old and new model runs are very similar because they use the same physics and dynamics, and only the lowest-level vertical motion is changed. This slight change leads to a small improvement in the WRF Model forecast. The results in this paper suggest that smoothing the terrain gradient instead of the terrain should be applied to the WRF Model over domains with steep terrain, such as the Hawaiian Islands.

The new boundary condition for calculating low-level vertical motion relies on the gradient of terrain data with much higher resolution than the model grid spacing. As the gradient increases, the vertical motion will also increase based on (3). If the grid spacing of the WRF Model is increased, the terrain gradient should also increase because of the added detail in the model. If the model grid spacing were the same as the terrain data $(50 \mathrm{~m})$, then calculating the gradient before the running the model (the new method) would give the same result as calculating the gradient in the model (the old method), but the computational overhead associated with such very high resolution would of course be restrictive. The gradient does not change over the timeframe of any weather simulation, so calculating the gradient before the simulation can always be done. This could potentially save time by eliminating the calculation for each point during each time step. Although the run time of the model runs were very similar for both methods in this study, using a very high-resolution domain could potentially see a marginal improvement in the very large model runtime by eliminating the gradient calculation. In the future, it would be useful to extend this study to investigate the impact of the terrain enhancement method on precipitation forecasts with differing model grid resolutions and in differing complex terrains. Such studies could also determine the impact of resolution on the relative cost in run time associated with implementing the method.

While the methodology presented in this research may not improve forecasts regarding whether or not precipitation will occur, it does show improvement in representing precipitation patterns and magnitudes during events. The problem of simulating precipitation is more complex than just improving a single element in the model. The improvements presented in this paper are small, but are generally moving in the correct direction. This method is not a complete solution to simulating precipitation, but instead represents an incremental improvement in precipitation forecasts in complex terrain.

This new boundary condition calculation can be incorporated into a future release of the WRF Model or it can be implemented in any numerical weather or climate prediction model. It should be tested with different boundary layer schemes, $w$-damping, and physics packages. It can also be applied over a larger area than just Oahu, such as the State of Hawaii and/or the continental United States.

Acknowledgments. This work was supported by the U.S. Dept. of Energy Cooperative Agreement DE-EE0003507 and the Hawaii State Barrel Tax-Environmental Response, Energy, and Food Security Tax. The authors would also like to acknowledge support from the Office of Mauna Kea Management, the National Science Foundation (ICER-1343761), and the Office of Naval Research under Award N00014-18-1-2166.

\section{REFERENCES}

Barstad, I., and F. Schüller, 2011: An extension of Smith's linear theory of orographic precipitation: Introduction of vertical layers. J. Atmos. Sci., 68, 2695-2709, https://doi.org/10.1175/ JAS-D-10-05016.1.

Birchard, T. R., 1999: Investigation of radar reflectivity-rainrate relationship in Hawaii. M.S. thesis, Dept. of Meteorology, University of Hawai'i at Mānoa, 64 pp.

Chen, Y., and A. J. Nash, 1994: Diurnal variation of surface airflow and rainfall frequencies on the Island of Hawaii. Mon. Wea. Rev., 122, 34-56, https://doi.org/10.1175/15200493(1994)122<0034:DVOSAA > 2.0.CO;2.

—, and J. Feng, 1995: The influences of inversion height on precipitation and airflow over the Island of Hawaii. Mon. Wea. Rev., 123, 1660-1676, https://doi.org/10.1175/1520-0493(1995) 123<1660:TIOIHO > 2.0.CO;2.

Crum, T. D., and R. L. Alberty, 1993: The WSR-88D and the WSR88D operational support facility. Bull. Amer. Meteor. Soc., 74, 
1669-1687, https://doi.org/10.1175/1520-0477(1993)074<1669: TWATWO $>2.0 . \mathrm{CO} ; 2$.

Doswell, C. A., III, H. Brooks, and R. Maddox, 1996: Flash flood forecasting, an ingredient-based methodology. Wea. Forecasting, 11, 560-581, https://doi.org/10.1175/1520-0434(1996) $011<0560$ :FFFAIB $>2.0$. CO;2.

Dudhia, J., 1989: Numerical study of convection observed during the winter monsoon experiment using a mesoscale two-dimensional model. J. Atmos. Sci., 46, 3077-3107, https://doi.org/10.1175/ 1520-0469(1989)046<3077:NSOCOD>2.0.CO;2.

Hartley, T. M., and Y. Chen, 2010: Characteristics of summer trade wind rainfall over Oahu. Wea. Forecasting, 25, 1797-1815, https://doi.org/10.1175/2010WAF2222328.1.

Hong, S.-Y., and J.-O. J. Lim, 2006: The WRF Single-moment 6-class Microphysics Scheme (WSM6). J. Korean Meteor. Soc., 42, 129-151.

Houze, R. A., Jr., 2012: Orographic effects on precipitating clouds. Rev. Geophys., 50, RG1001, https://doi.org/10.1029/ 2011RG000365.

Janjić, Z. I., 2002: Nonsingular implementation of the MellorYamada Level 2.5 Scheme in the NCEP Meso Model. NCEP Office Note 437, $66 \mathrm{pp}$.

Kodama, K., and G. Barnes, 1997: Heavy rain events over the southfacing slopes of Hawaii: Attendant conditions. Wea. Forecasting, 12, 347-367, https://doi.org/10.1175/1520-0434(1997)012<0347: HREOTS $>2.0 . \mathrm{CO} ; 2$.

_ , and S. Businger, 1998: Weather and forecasting challenges in the Pacific region of the National Weather Service. Wea. Forecasting, 13, 523-546, https://doi.org/10.1175/1520-0434(1998)013<0523: WAFCIT $>2.0 . \mathrm{CO} ; 2$.

Lin, Y., S. Chiao, T. Wang, M. Kaplan, and R. Weglarz, 2001 some common ingredients for heavy orographic rainfall. Wea. Forecasting, 16, 633-660, https://doi.org/10.1175/15200434(2001)016<0633:SCIFHO > 2.0.CO;2.

Lyman, R., T. Schroeder, and G. Barnes, 2005: The heavy rain event of 29 October 2000 in Hana, Maui. Wea. Forecasting, 20, 397-414, https://doi.org/10.1175/WAF868.1.
Marshall, J. S., and W. McK. Palmer, 1948: The distribution of raindrops with size. J. Meteor., 5, 165-166, https://doi.org/ 10.1175/1520-0469(1948)005<0165:TDORWS > 2.0.CO;2.

Mlawer, E. J., S. J. Taubman, P. D. Brown, M. J. Iacono, and S. A. Clough, 1997: Radiative transfer for inhomogeneous atmosphere: RRTM, a validated correlated-k model for the longwave. J. Geophys. Res., 102, 16663-16682, https://doi.org/ 10.1029/97JD00237.

Murphy, M., and S. Businger, 2011: Orographic influences on an Oahu flood. Mon. Wea. Rev., 139, 2198-2217, https://doi.org/ 10.1175/2010MWR3357.1.

Schär, C., and R. B. Smith, 1993: Shallow-water flow past isolated topography. Part I: Vorticity production and wake formation. J. Atmos. Sci., 50, 1373-1400, https://doi.org/10.1175/15200469(1993)050<1373:SWFPIT > 2.0.CO;2.

Schroeder, T. A., 1977: Meteorological analysis of an Oahu flood. Mon. Wea. Rev., 105, 458-468, https://doi.org/10.1175/15200493(1977)105<0458:MAOAOF>2.0.CO;2.

Smith, R. B., 2003: A linear upslope-time-delay model of orographic precipitation, mountain hydrology and water resources. J. Hydrol., 282, 2-9, https://doi.org/10.1016/ S0022-1694(03)00248-8.

— cipitation. J. Atmos. Sci., 61, 1377-1391, https://doi.org/ 10.1175/1520-0469(2004)061<1377:ALTOOP > 2.0.CO;2.

Van Nguyen, H., Y. Chen, and F. Fujioka, 2010: Numerical simulations of island effects on airflow and weather during the summer over the Island of Oahu. Mon. Wea. Rev., 138, 2253-2280, https://doi.org/10.1175/2009MWR3203.1.

Watson, C., and T. Lane, 2012: Sensitivities of orographic precipitation to terrain geometry and upstream conditions in idealized simulations. J. Atmos. Sci., 69, 1208-1231, https:// doi.org/10.1175/JAS-D-11-0198.1.

Wilks, D., 2011: Statistical Methods in the Atmospheric Sciences. 3rd ed. International Geophysics Series, Vol. 100, Academic Press, $704 \mathrm{pp}$ 